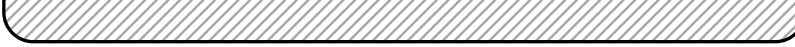

\title{
APRENDENDO SOBRE CRESCIMENTO E DESENVOLVIMENTO INFANTIL: RELATO DE EXPERIÊNCIA*
}

\section{Cristiane Chiericato**}

\section{APRESENTAÇÃO}

Como aluna do $4^{\circ}$ semestre do curso de graduação em enfermagem da Escola de Enfermagem de Ribeirão Preto da Universidade de São Paulo, no período de agosto à novembro de 1997 cursei a disciplina ERM-232 SAÚDE DA CRIANÇA E DO ADOLESCENTE, a qual será destacada neste estudo pelo fato de ter possibilitado o aprendizado de forma dinâmica em conteúdos teóricos e ações na área.

Falando detalhadamente dessa disciplina, de 120 horas, 8 créditos aula, ela tem como objetivo preparar o aluno para a assistência à criança desde o período neonatal até a adolescência, utilizando as ações básicas na promoção, prevenção e tratamento, tendo como referência o nível de atenção primário em saúde.

O programa da disciplina é desenvolvido através de 5 módulos: I- Crescimento e Desenvolvimento; IIImunização Infantil; III- Medidas de Prevenção na Infância e Adolescência; IV- Nutrição Infantil; VAssistência Integral à Saúde da Criança e do Adolescente.

Os conteúdos programáticos abordados em cada módulo são ministrados de forma gradual e dinâmica através de aulas expositivas, demonstrações práticas, vídeos, exercícios teórico-práticos, observações em creches e escolas, leitura e fichamento de textos, seminários, discussões em grupos e estudos de caso. A síntese dos conhecimentos e habilidades adquiridos nos quatro primeiros módulos é desenvolvida no último módulo, no qual os alunos executam a assistência de enfermagem em ações básicas na área de saúde da criança e do adolescente, em uma unidade básica de saúde do município.

No presente relato descrevo a experiência vivenciada no módulo I sobre Crescimento e Desenvolvimento.

\section{A ESTRATÉGIA DE ENSINO}

O conteúdo introdutório ao módulo foi desenvolvido através de seis aulas expositivas que abordavam sobre a situação social da criança e do adolescente, observação sistematizada da criança, exame físico, conceitos e vigilância do crescimento e desenvolvimento na infância, cuidados básicos aos recém-nascido e adolescência. Em cada aula eram comunicadas as referências bibliográficas básicas utilizadas, as quais estavam listadas no programa recebido por escrito, bem como informado a bibliografia complementar. Essas temáticas abordadas pelos docentes da área instrumentalizaram as atividades subseqüentes programadas no módulo.

Para que pudéssemos colocar em prática os conhecimentos teóricos adquiridos, foi nos proporcionado um estágio de 4 dias em escolas e creches, no qual desenvolvemos habilidades técnicas e reflexões sobre o processo de crescimento e desenvolvimento da criança e do adolescente, em suas relações com a família e instituições sociais. Cada aluno responsabilizava-se pela observação do crescimento e desenvolvimento de um lactente ou pré-escolar em creche e de um escolar de primeiro ou segundo grau,

* Trabalho orientado pela Professora Doutora Carmen Gracinda Silvan Scochi do Departamento de Enfermagem Materno Infantil e Saúde Pública da Escola de Enfermagem de Ribeirão Preto da Universidade de São Paulo

** Aluna do $5^{\circ}$ ano de graduação em enfermagem da Escola de Enfermagem de Ribeirão Preto da Universidade de São Paulo 
orientada por instrumento e sob a supervisão de uma docente, tendo-se como estratégia a associação entre teoria e prática. $\mathrm{O}$ instrumento direcionava a coleta de dados de identificação, aparência geral (estado emocional e de humor da criança, higiene), dados antropométricos, inspeção geral (pele, cabeça, pescoço, tórax, abdome, coluna vertebral, membros), desenvolvimento (motor, linguagem, relacionamento), inquérito alimentar (o quanto come, o que come, periodicidade, hidratação), e esquema de imunização.

Além disso, foram desenvolvidos seminários por 4 grupos de 7 alunos, havendo horários para leitura e discussão de textos e apresentado à todo grupo o resultado das observações feitas durante o estágio, fazendo assim a síntese teórico-prática do crescimento e desenvolvimento da criança e do adolescente.

A última atividade desenvolvida, individualmente, pelos alunos refere-se à um exercício escrito no qual solicitou-se um comentário sobre a afirmação que se segue:

"O crescimento e desenvolvimento da criança tem aspectos biológicos mensuráveis: exame físico, antropometria, gráfico para controle de crescimento, observação, testes, entre outros, e também estão relacionados com o setor saúde, condições de vida, família, escola. Com base nas aulas, nos textos e na observação realizada por você, comente sobre os aspectos que chamaram sua atenção".

\section{RETRATANDO A SÍNTESE DO APRENDIDO}

Face a experiência vivenciada, optei expressar o processo de aprendizagem sobre crescimento e desenvolvimento através de uma metáfora.

Assim, tomei como exemplo duas garotas bastante distintas. Sandra, ainda no útero materno, ouvia constantemente o canto materno e músicas de um CD quando a mãe acariciava o ventre e recebia a melhor alimentação possível; não poderia deixar de mencionar que a mãe é casada, exercia a profissão de advogada e jamais fez uso de álcool ou drogas. Enfim, todos os requisitos para um nascimento sadio e cheio de alegria. Agora Joana, que também está no útero de sua mãe, a qual é moradora de uma favela que não dispõe de água potável ou rua asfaltada, é alcoólatra e não tem condições de conseguir alimento todos os dias, sendo muitas vezes o almoço sua única refeição; ainda sobre a mãe de Joana, ela está sofrendo muita pressão porque já não consegue mais trabalhar de doméstica por estar com intercorrência no sétimo mês de gravidez. Gostaria de mencionar também que Sandra já tem seu próprio quarto e Joana irá dividir o seu com a mãe e mais três irmãos.

Partiremos então para o nascimento e o primeiro mês de vida destas duas crianças. Sandra, que nasceu de parto normal em um hospital privado, dispõe de quarto próprio no domicílio com dezenas dos mais variados brinquedos, das mais diversas cores, sendo um deles especial, importado, que toca música ao ser acionado algumas vezes; ela ainda é amamentada com o leite materno, que sabemos ser essencial para seu crescimento e desenvolvimento. A mesma ainda tem fraldas descartáveis e recebe cuidado especial no seu banho diário feito com o melhor sabonete do mercado. Quando a mãe de Sandra mexe suas mãos na sua frente, a menina responde acompanhando sempre os movimentos com os olhos. Falando um pouco de Joana, que nasceu em um hospital público, de cesariana, pois sua mãe passou mal minutos antes do parto, ela não tem os mesmos privilégios de Sandra. Joana não tem o leite materno todo o momento devido ao fato de que sua mãe tem que sair para trabalhar, também não tem quem troque suas fraldas de pano sempre que estão sujas, tendo assim uma dermatite de contato constante em seu períneo. A pobre menina passa o dia com seus irmãos tentando sobreviver sem o carinho ou afeto de uma mãe por perto.

Passando agora para a idade de 2 anos, observaremos Sandra e Joana. A primeira tem perninhas grossas e cheias de dobrinhas, mantém consigo um ursinho inseparável e que não divide com ninguém, gosta de conversar, ouvir estórias infantis e vive dizendo que quando crescer vai ser "dotôla" como papai. Já Joana, que de tão magrinha podemos chegar a pensar que tem apenas um ano, ela quase não conversa, tem os cabelos quebradiços e em banda e não se relaciona muito bem com as outras crianças da creche. Muito raramente brinca de bonecas e a maior parte do tempo fica sentada em um triciclo parado, apenas olhando as outras crianças brincarem.

Quanto a alimentação, Joana quase não tem o que comer em casa por isso sua mãe a deixa o tempo todo na creche ou, as vezes, na casa de sua patroa para que ela possa comer algo que a alimente e não mais aquela papa de farinha de mandioca. Por outro lado, Sandra, que já consegue comer sozinha, usa e abusa de uma alimentação super saudável e de guloseimas quase todos os dias.

E como está a saúde de Sandra e Joana? Bem, a de Sandra está muito bem e não poderia estar melhor, afinal seu pediatra é o próprio pai e quando ele nota 
qualquer anormalidade na filha já logo trata de cuidar para evitar que algo de grave possa acontecer. E com Joana, será que acontece o mesmo? Acredito que não. O que ocorre quando ela está doente é bem diferente da outra criança, pois quando apresenta uma tosse, diarréia ou está com outro sintoma que não dá mais para esconder de ninguém, a mãe leva-a ao posto de saúde para saber o que há de errado. $\mathrm{O}$ médico a examina, faz o diagnóstico e receita alguns medicamentos para a menina tomar. $\mathrm{O}$ posto fornece os medicamentos à mãe que sai dali bastante satisfeita de que não é nada grave; o único problema encontrado é que a mãe esqueceu a dosagem do medicamento prescrito e ao recorrer à receita lembra de um "pequeno" detalhe: não sabe ler. O que acontece agora com a pequena Joana? Podemos dizer que a menina melhorou por força de vida própria e por uma dosagem qualquer dos medicamentos recebidos e administrados.

Com todas estas observações, não fica difícil imaginar o futuro de cada uma dessas meninas, o que passará pela cabeça de cada uma delas e o que a vida tem a lhes oferecer.

Passados alguns anos, encontramos agora de um lado Sandra, cursando o primeiro ano da faculdade de medicina com apenas 17 anos e aparentando uma beleza sem igual; de outro lado está Joana, ainda na oitava série com a mesma idade de Sandra, a pobre quase não cresceu e tem muita dificuldade nos estudos devido também ao fato de que quase não tem tempo para os estudos, uma vez que passa o dia todo nas ruas como catadora de papel. Joana tem estampada nas mãos a marca de sua vida tão difícil e dura de se contar. Mas a jovem carrega consigo um grande triunfo: o sonho de um dia poder ser médica como a filha de sua patroa.

Bem, pode ser que o relato seja uma ficção mas que não está tão longe assim da realidade. O que gostaria de expor através deste paralelo, sintetizando o apreendido na disciplina, é que não basta nascer para se possuir uma vida, é necessário todo um aparato social, biológico e psicológico para evoluir e adquirir um bom crescimento e desenvolvimento, é todo um contexto de saúde envolvendo alimentação, escolaridade, moradia, saneamento e salários de certa forma regulares (apesar de sabermos que isto quase nunca acontece em determinadas classes sociais). É preciso harmonia destes fatores juntos para se tentar obter um crescimento e desenvolvimento saudável e digno, um direito de cidadania. 